\title{
LA POLÍTICA EXTERIOR Y LA POLÍTICA DE COOPERACIÓN: PARADOJAS DEL CASO ESPAก̃OL
}

\section{Foreign policy and aid policy: paradoxes of the Spanish case}

\author{
José Ángel Sotillo \\ Universidad Complutense de Madrid \\ Departamento de Derecho Internacional Público y Relaciones Internacionales
}

0 Autores

sotillo@ucm.es

La cooperación internacional para el desarrollo fue uno de los elementos más importantes de la política exterior española. Como manifestación de la solidaridad, contribuía al desarrollo de países y pueblos, potenciaba las relaciones exteriores, reflejaba la pluralidad de actores de la cooperación y afirmaba la presencia española a favor del multilateralismo. Con la crisis como telón de fondo, en los últimos años no sólo ha habido un gran descenso de la ayuda española, sino que ha perdido peso en la acción exterior del Gobierno y de otras instituciones, debilitando el papel de España en el mundo.

España, política exterior, cooperación internacional para el desarrollo, marca España

Spain, foreign policy, international development cooperation, Spain Brand

Q Key mords

Recibido: 07/08/2014. Aceptado: 20/09/2014

Resumen

Fechas

International development co-operation has always been a cornerstone of Spanish foreign policy. Not only has it been an expression of solidarity contributing to the development of countries and peoples, it has also bolstered foreign relations and, by reflecting the plurality of actors involved in International Cooperation, it has further affirmed Spain's position in favour of multilateralism. Given the scenario of the present economic crisis there has been a noticeable drop in Spanish foreign aid, whose consequence has been a loss of influence in the Government's and other Institution's external actions, weakening Spain's role in the world. 


\section{Introducción}

Este artículo tiene como objetivo analizar los cambios en la política española de cooperación para el desarrollo y el impacto que la crisis ha tenido -y tiene- sobre dicha política.

Sobre la base de la disminución de los fondos destinados a cooperación, se explicitarán las consecuencias tanto internas como externas y el impacto de los recortes en la presencia de España en el mundo.

Desde ese presente negativo, se concluirá con las opciones que se están utilizando para redefinir la cooperación, destacando la crucial importancia que una auténtica cooperación tiene para una buena parte de la población mundial.

\section{Qué supone para España la cooperación para el desarrollo}

La cooperación para el desarrollo se incorporó de forma tardía a las relaciones exteriores de la España que caminaba hacia la democracia tras la muerte de Franco. El fin del aislamiento internacional, la recomposición de todo el mapa exterior, la incorporación a organismos internacionales y, especialmente, el ingreso en la Europa unida eran los objetivos fundamentales de la política exterior de la transición.

Cumplidos algunos de esos objetivos y comenzando a tener avances en el terreno económico se fueron poniendo en marcha, lentamente, las primeras acciones de ayuda al desarrollo, que se hacían en connivencia con los intereses de la internacionalización de las empresas españolas, cuya mayor manifestación fueron los créditos FAD (Fondo de Ayuda al Desarrollo).

Será en los años 80 cuando la ayuda vaya tomando forma y se dote de una dimensión institucional que la convertirá en una de las dimensiones de la política exterior; uno de los pasos más importantes será la creación, en 1988, de la Agencia Española de Cooperación Internacional (AECI) y su despliegue exterior por medio de las Oficinas Técnicas de Cooperación (OTC).

Los años 90 fueron testigos de las movilizaciones de una parte importante de la sociedad española que reclamaba el objetivo del $0.7 \%$, y una mayor presencia en la formación y definición de la política de cooperación, teniendo como resultado, entre otros, un mayor compromiso por parte del Gobierno y de otras instituciones, así como la creación del Consejo de Cooperación.

Bajo el impulso del preámbulo de la Constitución Española ("Colaborar en el fortalecimiento de unas relaciones pacíficas y de eficaz cooperación entre todos los pueblos de la Tierra”) y tras varios intentos por los Gobiernos del PSOE, se aprobará, el 7 de julio de 1998, con el Gobierno del Partido Popular, la Ley de Cooperación Internacional para el Desarrollo. En sus antecedentes se afirma que "constituye un aspecto fundamental de la acción exterior de los Estados democráticos" y el artículo 3 dice que "La política de cooperación internacional para el desarrollo es parte de la acción exterior del Estado y se basa en el principio de unidad de acción del Estado en el exterior".

La cooperación no es exclusiva de la Administración General del Estado (AGE), sino que en ella participan de forma muy activa distintas entidades subestatales, destacando siempre el caso español como una referencia en el ámbito de la cooperación descentralizada.

Un salto cualitativo se da en 2004, tras la victoria electoral del PSOE, cuando la política de cooperación sube de nivel en el estrato gubernamental, hecho que se visibiliza en el cambio de 
nombre del Ministerio, que pasará a ser de Asuntos Exteriores y de Cooperación y con el nuevo papel de la Agencia Española de Cooperación Internacional para el Desarrollo (AECID).

La cooperación pasa a ser, por tanto, uno de los vectores fundamentales de la presencia de España en el mundo no sólo por el compromiso de alcanzar el $0.7 \%$, sino como uno de los pilares para llevar a cabo un multilateralismo activo y eficaz.

Se escenifica la cooperación, de este modo, como una de las principales manifestaciones del 'poder blando', que viene a potenciar la imagen y la presencia de España en el mundo, junto a otras como las Operaciones de Mantenimiento de la Paz.

Otro motivo importante para reforzar la política de cooperación fue el hecho de considerarse como una política consensuada de Estado, más que de Gobierno, y consolidarla desde la presencia ciudadana, mediante el diálogo con interlocutores de la sociedad civil. El documento más significativo en este caso fue el Pacto de Estado contra la Pobreza, suscrito por el Gobierno, todos los partidos con representación parlamentaria y la Coordinadora de ONG para el Desarrollo, el 19 de diciembre de 2007.

Sin embargo, el tsunami de la crisis se ha afectado, entre otras muchas cosas, a la política de cooperación, que ha sufrido un cambio radical desde el año 2010.

Aun con un corto recorrido, la cooperación española se convirtió, por tanto, en una de las bazas principales de la presencia en el exterior, y consolidó una imagen de país solidario, tanto para hacer frente a situaciones de especial gravedad tras desastres o conflictos, como para contribuir, no sin algunas incoherencias, a una mayor y mejor desarrollo a escala global.

Manuel de la Iglesia-Caruncho, en su artículo sobre "Política exterior y política de cooperación: ¿amistades peligrosas?”, publicado en abril de 2011, explicaba la tendencia por la cual España transitaba desde el modelo en el que la política de cooperación es un instrumento de la política exterior, al de ser, entre otros, un elemento definitorio de dicha política (el tercer modelo es que la política de cooperación sea una política de desarrollo). Hoy vemos como la cooperación, muy reducida en lo cuantitativo, se reafirma como una acción al servicio de los intereses de la política exterior del Gobierno y se aleja, por tanto, de ser una política que contribuya decisivamente a promover el desarrollo.

\section{El impacto de la crisis}

Justo en el año en el que comenzaba una crisis que iba a afectar de manera significativa a la vida económica, social y política española, en 2008, España tocaba techo en su aportación de Ayuda Oficial al Desarrollo (AOD), con una cantidad de 4.761 millones de euros, lo que suponía el $0.45 \%$ de la Renta Nacional Bruta.

Durante un tiempo, los máximos responsables del Gobierno manifestaron que no tenían intención de reducir la ayuda española; así lo hacía el Ministro de Asuntos Exteriores y de Cooperación, Miguel Ángel Moratinos (2010), al explicar el 14 de abril de 2010 que el 0,7 constituye "uno de los objetivos irreversibles del Gobierno... Y lo vamos a cumplir".

Sin embargo, pocos días después, el 12 de mayo de 2010 -tras una reunión extraordinaria del Eurogrupo en relación con el rescate de Grecia y la situación de los mercados financieros-, el Presidente José Luis Rodríguez Zapatero (2010) anunció durísimas medidas de ajuste, entre las que se incluye "una reducción, entre 2010-2011, de 600 millones de euros en Ayuda Oficial al Desarrollo".

\section{El tsunami de la crisis se ha llevado, entre otras muchas cosas, a la política de cooperación, que ha sufrido un cambio radical desde el año 2010}


Las elecciones del 20 de noviembre de 2011 llevan de nuevo al PP, dirigido por Mariano Rajoy, a La Moncloa. En su discurso de investidura, de 19 de diciembre de 2011, centrado obviamente en cómo hacer frente a la crisis, hay espacio para definir la política exterior, aunque el presidente se refiere brevemente a ella ("Tenemos que resolver qué lugar queremos que España ocupe en el mundo... para competir por un puesto de primera fila en un mundo nuevo." (Rajoy, 2012), sin hacer mención explícita a la cooperación.

La remodelación de la estructura gubernamental, por medio del Real Decreto 1823/2011, de 21 de diciembre de 2011 -y el Real Decreto 342/2012, de 10 de febrero, por el que se desarrolla la estructura básica del Ministerio de Asuntos Exteriores y de Cooperación-, lleva a la creación de la Secretaría de Estado de Cooperación Internacional y para Iberoamérica, a la que está adscrita la AECID (junto al Instituto Cervantes); de la Secretaría de Estado dependerá la Secretaría General de Cooperación Internacional para el Desarrollo. Con el cambio, desaparece la Dirección General de Planificación y Evaluación de Políticas para el Desarrollo (DGPOLDE), que pasa a ser la División de Evaluación de Políticas para el Desarrollo y Gestión del Conocimiento.

En su primera comparecencia ante la Comisión de Asuntos Exteriores del Congreso, el 22 de febrero de 2012 - ese mismo día se había reunido con el empresario y filántropo Bill Gates-, el ministro García-Margallo, tras realizar algunas reflexiones sobre la cooperación y por qué hay países pobres y ricos y que la cooperación no se limita sólo a aportar recursos económicos, resaltaba el papel de la gobernanza y señalaba las prioridades geográficas y sectoriales de la cooperación española, aunque sin hacer mención alguna a cantidades o porcentajes previstos. A las preguntas sobre esa cuestión, responde "Es extraordinariamente doloroso para mí que el recorte se haya producido en cooperación y le voy a decir en qué se recorta. La cooperación ha pasado de 4.728 millones en 2009 a unos 3.200 millones en 2011; un 0,3 en porcentaje el año en que se despidió el Gobierno socialista, muy lejos del 0,7. En estos momentos se ha producido un recorte de 1.000 millones en cooperación, un recorte sensible que agradezco a la amabilidad del ministro de Hacienda. Pero, en fin, eso es lo que hay" (García-Margallo, 2012).

Sin embargo, la intervención más llamativa del ministro responsable de la cooperación se produjo ante la Comisión de Cooperación Internacional para el Desarrollo, en el Congreso de los Diputados, el 14 de marzo de 2012, al afirmar que "cuando se hace un presupuesto, que por definición en economía es administración de recursos escasos, hay que elegir una opción. Créame que recortar la cooperación para mí es una opción extraordinariamente dolorosa, pero la otra opción a lo mejor es recortar las pensiones o cerrar ambulatorios, entonces hay que hacer una elección política" (García-Margallo, 2012). Afirmación que va en paralelo a uno de los mantras para hacer frente a la crisis: hacer más con menos ${ }^{1}$.

Conviene ir más allá e intentar indagar en el ideario más conservador sobre qué se entiende por cooperación y, sobre todo, cómo se consigue el desarrollo. Nada mejor que bucear en las aguas de la Fundación para el Análisis y los Estudios Sociales (FAES) para encontrar dicho argumentario. En el terreno que nos ocupa, por ejemplo, sirva el texto elaborado por Percival Manglano, que fue coordinador de estudios de la Fundación FAES y que desempeñó el cargo de Consejero de Economía y Hacienda en el Gobierno de la Comunidad de Madrid presidido

l Parafraseando esos términos, la parte 4 de la obra coordinada por Ignacio Molina, España en el mundo durante 2014: perspectivas y desafíos, Elcano Policy Paper 2/2014, 31 de marzo de 2014, se titula: “¿Menos con menos? Cooperación internacional, poder blando e imagen exterior". 
por Esperanza Aguirre. Para Manglano (2007), en "La ayuda al desarrollo como incentivo del buen gobierno", el debate ideológico de fondo sobre las causas y soluciones de la pobreza en el mundo se focalizan en el enfrentamiento entre 'redistribuidores' (sic) y liberales. Creo que no hace falta decir de qué lado está Manglano. Cito textualmente: "La estrategia de comunicación de los redistribuidores es altamente eficaz. Sus mensajes se dirigen ante todo al corazón de los ciudadanos de los países ricos: "nosotros tenemos mucho; ellos no tienen nada; hay que compartir”. Los mensajes se transmiten en tono alegórico y festivo, en manifestaciones y movilizaciones marcadas por la denuncia, la música y la diversión. La puesta en escena está siempre muy cuidada y razonada, con un alto grado de diseño ${ }^{2}$.

En esa línea, el IV Plan Director 2013-2016 (se aprueba en Consejo de Ministros el 21 de diciembre de 2012): "se caracteriza por presentar un enfoque REALISTA; una determinación por REDISEÑAR nuestra cooperación; la orientación hacia RESULTADOS; y RENDICIÓN de cuentas".

El Plan Director 2013-2016 refleja claramente tanto el impacto de la crisis como la falta de voluntad para mantener la cooperación como una prioridad para el Gobierno: "No es posible en este escenario mantener ciertos compromisos internacionales, como el adquirido en el seno de la UE para alcanzar el 0'56\% de AOD/RNB (objetivo establecido para 2010), o la meta largamente reivindicada del 0'7\% AOD/RNB. Pero sigue siendo compromiso de este Gobierno poder recuperar umbrales como los de ejercicios precedentes, magnitudes que no sólo dependerán del esfuerzo de la AGE, sino del de todos los actores de la Cooperación Española.

Cuando las condiciones lo permitan, estaremos en disposición de hacer previsiones de crecimiento con mayor seguridad. Serán los presupuestos anuales las que nos permitirán concretar aquellas metas que ahora no es posible precisar".

El Plan Director resalta otra de las prioridades del Gobierno en cooperación, expuesta tras el marco general de fomentar alianzas estratégicas con distintos sectores, como es la importancia que se otorga al sector privado y la creación de alianzas público-privadas.

En su discurso ante la $68^{\mathrm{a}}$ sesión de la Asamblea General de la ONU -el 25 de septiembre de 2013-, Mariano Rajoy (2013) defendió las razones por las que España opta a ser miembro del Consejo de Seguridad en el bienio 2015-2016. El presidente hizo hincapié en la aportación española al mantenimiento de la paz, la seguridad internacional y al desarrollo, siendo también el sexto contribuyente al sistema de Naciones Unidas y el octavo donante a la ayuda humanitaria. En su discurso, hizo un balance positivo del pasado, aunque no aporta novedades concretas sobre el futuro de la cooperación española en el marco de las acciones internacionales en este ámbito, mirando ya el escenario post 2015, tras la rendición de cuentas del cumplimiento (o no) de los Objetivos de Desarrollo del Milenio. Afirmaba con rotundidad que "la AOD no es caridad sino una inversión solidaria en un futuro común porque lo que está en juego es el bienestar global”.

Otro evento importante que contó con la presencia del presidente Rajoy y del Secretario General de la ONU, Ban Ki-Moon, fue la "Reunión de Alto Nivel sobre Hambre, Seguridad Alimentaria y Nutrición: hacia una agenda de desarrollo post 2015”, el 4 de abril de 2014. España ejerce de país anfitrión, junto a Colombia, y, entre otros, participan representantes de 17 agencias de Naciones Unidas.

2 Ver el texto completo en

http://www.fundacionfaes.org/record_file/filename/464/00068-08_-_la_ayuda_al_desarrollo_como_incentivo.pdf

\section{El Plan Director} 2013-2016 refleja claramente tanto el impacto de la crisis como la falta de voluntad para mantener la cooperación como una prioridad para el Gobierno 
En todo caso, los datos que conocemos no respaldan las demostraciones de buena voluntad del Gobierno. En los presupuestos para 2014, la AOD prevista es de 1.814,98 millones de euros, lo que supone un $0.17 \%$ de la Renta Nacional Bruta, regresando a datos de 1990. Según datos del Comité de Ayuda al Desarrollo, ahora ocupa el penúltimo puesto de los donantes miembros de ese Comité, sólo por delante de Italia, cuya aportación es del 0,13\% de su RNB. La media en la UE es de $0,5 \%$. Incluso Portugal $(0,27 \%)$ e Irlanda $(0,48)$, países con una coyuntura económica similar a la española, aportan más.

Así lo refleja el escrito de Jon Lomøy, de 13 de diciembre de 2013, dirigido a los Delegados y Observadores del Comité de Ayuda al Desarrollo, con motivo de la revisión a medio plazo de la Ayuda Oficial al Desarrollo española.

El siguiente cuadro visibiliza el cambio en los fondos destinados a AOD:

\section{Aportación de españa}

En $\%$ de la RNB.

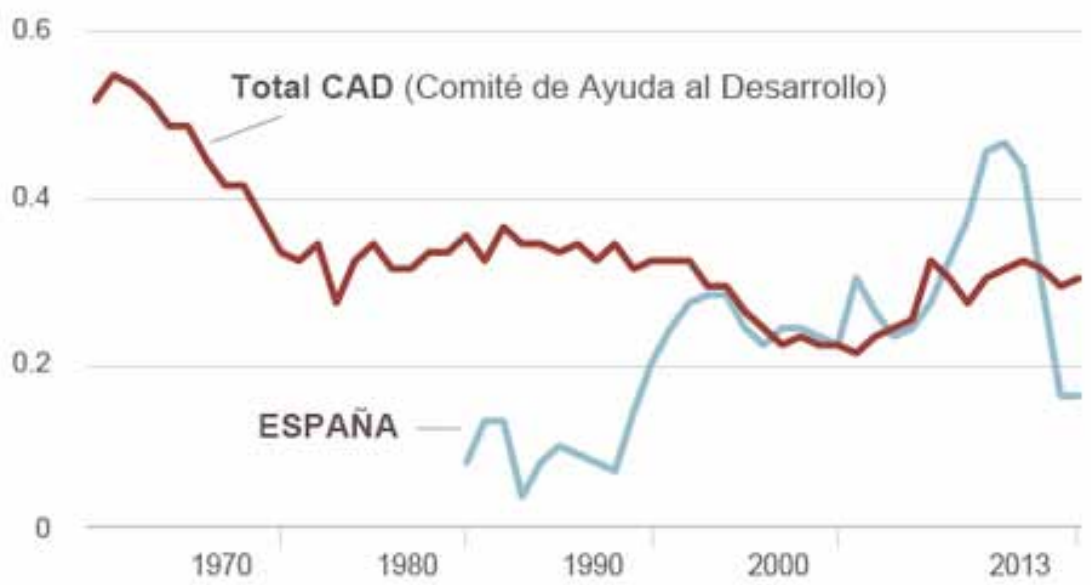

Fuente: Comité de Ayuda al Desarrollo

Oxfam Intermón, que lleva realizando el análisis de la cooperación española desde hace muchos años, anunció el correspondiente a 2013 con el siguiente titular: "España líder indiscutible de los recortes en cooperación”.

Un dato a tener muy en cuenta es que la reducción afecta de forma muy significativa al Ministerio de Asuntos Exteriores y de Cooperación -y muy especialmente a la AECID- dado que España debe mantener las aportaciones a organismos internacionales y la parte que le corresponde para financiar la cooperación de la Unión Europea. De ello deriva que, desglosando las cuentas, el Ministerio de Hacienda sea el responsable del 50\% del total de la ayuda española que es competencia de la Administración General del Estado, el MAEC del 32.5\% y el de Economía del $14.47 \%$. La AECID ve reducido su presupuesto en un 70\% con respecto a 2011. Los fondos para ONG caen a su vez un 50\% (en 2013 fue del 17\% y en 2012 del 35\%).

Al mismo tiempo, adquieren mayor protagonismo entidades del sector privado, en especial las Fundaciones, incluso aquellas que cuentan con un componente público, como es el caso de la Fundación Internacional y para Iberoamérica de Administración y Políticas Públicas (FIIAPP), la Fundación Carolina, Tragsa o P4R. 


\section{Repercusiones internas y externas del descenso de la ayuda al desarrollo}

Los drásticos recortes en la cooperación española han tenido un gran y muy grave efecto negativo, en la doble dimensión interna y externa.

$\mathrm{Al}$ interior, se ha devaluado la política de cooperación, si la comparamos con el nivel que tuvo unos años atrás. Además del recorte brutal que ha sufrido desde 2010, ya con el Gobierno del Partido Popular tanto en la reestructuración departamental como el escaso apoyo que cuenta, hacen que su peso político sea mucho menor y haya perdido la intensidad que llegó a tener.

El dilema del ministro es falso: según el informe World Health Statistics 2014 publicado por la OMS (2014), España, que en la lista de 2013 ocupaba el décimo puesto mundial en número de médicos por cada 10.000 habitantes, pasa ahora al decimosexto; las universidades públicas han registrado 45.241 alumnos menos en los dos últimos años (-3,3\%) después de varios consecutivos de crecimiento de las matriculaciones, según el avance estadístico del curso 2013-2014 publicado por el Ministerio de Educación.

Es decir, se han aplicado los recortes y ajustes a todas las políticas públicas, incluyendo la de cooperación.

A los 25 años de su creación, el papel que debía desempeñar la AECID hoy está puesto en cuestión; por eso resultan poco convincentes las palabras que recoge la propia página de la institución: "La AECID, como institución del Ministerio de Asuntos Exteriores y de Cooperación del Gobierno de España, tiene como objetivo el fomento y la gestión de las políticas públicas de la cooperación internacional española. Durante estos años, la Agencia ha establecido alianzas internacionales y reforzado las relaciones de España con otros países e instituciones como las agencias de las Naciones Unidas. Esta labor ha contribuido al reconocimiento de una Marca España de solidaridad y cooperación, destacando a España como socio comprometido con la sociedad internacional".

Como telón de fondo y en línea con la argumentación ideológica del Partido que sustenta el Gobierno, se ha producido una economización y tendencia privatizadora de la cooperación española. Desde la Plataforma "2015 y más”3 se viene denunciando esta situación que, como muestra, encontramos la creación del Fondo de Promoción del Desarrollo (FONPRODE), puesto más al servicio de los intereses comerciales que como auténtico instrumento de la cooperación española.

Como antes comentábamos, el descenso de los fondos que gestiona la AECID no sólo tiene una repercusión cuantitativa, sino que lleva consigo una gran descapitalización del papel central que ocupaba en la cooperación española y una gran merma en sus recursos humanos.

Uno de los sectores más afectados es el de las ONGD, mucho más afectadas en la medida en que buena parte de ellas tenían una gran dependencia de fondos públicos. La caida de estos, tanto los de la Administración central como especialmente los fondos de las Comunidades Autónomas, han llevado a las ONGD a la búsqueda de recursos alternativos, a la fusión entre algunas de ellas, cuando no a su desaparición.

3 Ver la página http://www.2015ymas.org/; entre otros, se puede consultar el texto de Lou Pingeot sobre La influencia empresarial en el proceso post-2015.

Uno de los sectores más dañados es el de las ONGD, mucho más afectadas en la medida en que buena parte de ellas tenían una gran dependencia de fondos públicos 
En declaraciones de la presidenta de la CONGDE-España, Mercedes Ruiz-Giménez (2010), el 10 de octubre de 2010 (incluidas en "AECID, en peligro de desaparición"): "Las subvenciones a ONGD descienden en un 65\%, 50 millones menos que el año pasado", además, "los convenios que firmamos con el Estado son acciones importantes para el desarrollo con programas de 4 años”. Se critica no sólo el descenso de las cifras, sino la dejación del Gobierno en esta política: "Estas cuentas nos preocupan más allá de lo que suponen para las ONG. Rajoy ha prometido ante la ONU que, según se vaya recuperando la economía se incrementaría la ayuda, pero a pesar de anunciar una mejoría, seguimos descendiendo... Es una incoherencia con lo que esta publicitando el Gobierno. A Rajoy se le llena la boca hablando ante las Naciones Unidas de lo que España contribuye en la lucha pobreza y en la defensa de los Derechos Humanos y en Cooperación al Desarrollo, mientras da un golpe nuevamente a los presupuesto para cooperación”.

Un efecto añadido es que la ONGD reorientan sus actuaciones para atender a las necesidades básicas de una buena parte de la ciudadanía española, que no puede acceder a ellas. Y no sólo eso, sino que denuncian esas situaciones no sólo como carencias motivadas por la crisis, sino que son la punta de lanza de la desigualdad y afectan a derechos fundamentales, e intentando que el Gobierno cambie de actitud. Así, el 26 de noviembre de 2013, representantes de Amnistía Internacional, Greenpeace y Oxfam Intermón presentaban al Jefe de Gabinete de Presidencia, Javier Moragas, propuestas sobre "Derechos, Desigualdad y Medio Ambiente" y un "Decálogo de medidas contra la crisis" para "Combatir la crisis con dignidad y derechos", insistiendo en que sí hay dinero y denunciando el fraude y la evasión por medio de paraísos fiscales (Amnistía Internacional, Greenpeace \& Oxfam Intermón, 2013). Poco después, el 19 de diciembre, la presidenta de la CONGDE, en representación de las entidades que agrupa, denunciaba que los presupuestos de 2014 "tiran los derechos de los españoles a la basura y abocan a millones de personas a situaciones de pobreza, desigualdad e inseguridad humana" (Ruiz-Giménez, 2013).

La mayor concienciación sobre el impacto de la crisis llega a muchos lugares y así el dibujante Forges no sólo nos reclama que no nos olvidemos de Haití, sino que además no nos olvidemos de aquí.

A ello hay que añadir que también ha descendido o casi desaparecido el consenso en el que se basaba esta política y es prácticamente inexistente el diálogo con entidades representativas de la sociedad civil que, a pesar de todas las dificultades, siguen reclamando al Gobierno que no descienda la solidaridad. Incluso, y como consecuencia del impacto en muchas personas de los efectos de la crisis, se detecta una mayor concienciación con la situación que padecen millones de personas en el mundo.

Es más, según las encuestas, los españoles siguen apoyando mayoritariamente que se mantenga la ayuda al desarrollo. Así lo hace el Eurobarómetro al consultar sobre Ayuda al Desarrollo y Objetivos de Desarrollo del Milenio de la UE (Comisión Europea, 2013). También la que realiza la sección sobre desarrollo "Planeta Futuro", del diario El País (Toharia, 2014).

En paralelo, la presencia exterior que conlleva la cooperación internacional ha descendido drásticamente. Es cierto que hace unos años se podía calificar como exagerado el número de países a los que España suministraba ayuda, pero los recortes han llevado a que el número de países prioritarios, según el Plan Director 2013/2016, haya quedado reducido a 23 (América Latina y Caribe: Bolivia, Colombia, Cuba, Ecuador, El Salvador, Guatemala, Haití, Honduras, Nicaragua, Paraguay, Perú y República Dominicana; Norte de África y Oriente Próximo:
Ha descendido o casi desaparecido el consenso en el que se basaba esta política y es prácticamente inexistente el diálogo con entidades representativas de la sociedad civil 
Mauritania, Marruecos, Población Saharaui y Territorios Palestinos; África Subsahariana: Mali, Níger, Senegal, Etiopía, Guinea Ecuatorial y Mozambique; Asia: Filipinas)" también ha habido cierres de Oficinas Técnicas de Cooperación (OTC). En su estructura exterior, la AECID cuenta con 33 Oficinas Técnicas de Cooperación (OTC), 12 Centros Culturales (CC), 4 Centros de Formación (CF).

Si la cooperación era uno de los referentes de la presencia internacional española, repercutía positivamente en la imagen externa de España y constituía uno de los 'avales' para potenciar nuestra relevancia internacional ${ }^{5}$, su caída pone en cuestión todo lo anterior.

Además, nuestra imagen se devalúa en consonancia con el descenso de aportaciones a fondos multilaterales, como el Fondo Global contra el SIDA, la malaria y la tuberculosis, o la reducción de fondos para ayuda humanitaria para atender a situaciones de catástrofes o conflictos.

Un buen reflejo de esa situación nos lo ofrece Gonzalo Fanjul (2012) en una entrada en su blog, publicado el 27 de septiembre de 2012, "No hay Consejo de Seguridad sin cooperación”, en el que plantea la disyuntiva de que el Gobierno garantice "el sostenimiento básico del sistema de ayuda y obtener resultados razonables en un número reducido de escenarios”, o, el más drástico pero también razonable "cerrar el chiringuito: "amigos de la ONU, España tiene otras prioridades y se retira durante un tiempo de este juego".

Como Secretario General de Cooperación Internacional para el Desarrollo, Gonzalo Robles (2014), no cree que España haya perdido peso internacional al rebajar la cooperación, ni que ello haya afectado a la imagen de España; en una extensa entrevista publicada por el diario El País, el 16 de enero de 2014, afirma: "Llevo dos años recorriendo todos los organismos internacionales y no solo no he sentido en ningún sitio ninguna crítica hacia España, sino al revés, he sentido una enorme comprensión. De ninguno de los burós de los que España estaba formando parte, nos han echado, en todos seguimos estando. Cito dos hechos importantes que marcan si tenemos peso no: cuando Naciones Unidas ha tenido que adjudicar a un país, de los muchos que lo habían pedido, la tarea de hacer consultas para la agenda post 2015, España fue elegida. Para tener aquí a todas las agencias de Naciones Unidas con el secretario general a la cabeza y poder hacer lo que creo que fue una brillante jornada sobre seguridad alimentaria y nutrición. Es decir, se le reconoce a España una autoridad. El segundo es que después de Rio se decide crear un grupo de trabajo sobre los futuros Objetivos de Desarrollo Sostenible. Había muchos candidatos y España fue elegida. Yo soy miembro, yo ocupo una silla en ese grupo que está preparando los ODS”.

Lógicamente, desde otros sectores la valoración es muy distinta, al mostrar que el descenso de la cooperación española no sólo afecta directamente a un importante grupo de población en distintos lugares del planeta, sino que empeora la imagen de España. Así lo manifiesta Marta Arias (2014), Directora de Sensibilización y Políticas de Infancia de Unicef, al afirmar que "la

4 A este respecto, Pablo Bandeira afirma que "el Gobierno de España sigue seleccionando tanto a los principales agentes receptores de ayuda, como a los instrumentos específicos de financiación, de forma opaca y discrecional, con criterios no relacionados con su eficacia ni su transparencia", en la mesa redonda sobre "La Cooperación Internacional del Gobierno de España en la presente legislatura”, DECIDE (Democracia, Ciudadanía, Desarrollo), 10 julio 2014.

5 El 23 de abril de 2014 se publicó el Informe Elcano de Presencia Global 2014 (elaborado por Iliana Olivié, Manuel Gracia y Carola García-Calvo) que recoge un análisis pormenorizado de las distintas tendencias de presencia global sobre la base de datos del índice para 2013. En la página web del Real Instituto Elcano también se puede consultar el Observatorio Imagen España.

\section{Si la cooperación era uno de los referentes de la presencia internacional española, su caída pone en cuestión todo lo anterior}


cooperación es una fuente de prestigio para España que no debe perderse. Aunque nuestra meta siempre es y no debe ser otra que la solidaridad, el reconocimiento internacional es un logro secundario de estos proyectos". Arias también insiste en que deben explicarse los resultados de la cooperación y qué se hace con la ayuda y en la promoción de campañas, como "Ahora no podemos parar - Razones para reconstruir la cooperación española”, para recuperar el interés de la sociedad y de las Administraciones Públicas por la cooperación.

También se critica que la ayuda se utilice, desde la cobertura de la Marca España, para vincularla estrechamente a la promoción del crecimiento económico. Para Natalia Millán (2014), "de acuerdo con las declaraciones del Presiente y sus Ministros, se podría decir que la Marca España pretende mejorar la imagen del país en el exterior a través de una apuesta eminentemente económica que posee tres vertientes: 1) mejorar el clima inversor en España para que (en palabras de Margallo), el "capitalista encuentre simpático" invertir aquí; 2) optimizar la "competitividad" de los productos españoles para incrementar las exportaciones; 3) apoyar-casi de manera incondicional y con diferentes instrumentos, incluyendo los de la ayuda al desarrollo- a las empresas españolas en el exterior". ${ }^{6}$

Dicho lo cual, evidentemente la cooperación española, aun reducida, ha seguido funcionando y, como se comentaba antes, se han dado pasos como la renovación, en colaboración con el Programa de las Naciones Unidas para el Desarrollo (PNUD), del Fondo Español para el Logro de los Objetivos del Milenio, recordando que en 2007 el Gobierno aportó 528 millones de euros para los primeros cinco años.

Con el apoyo de la Cooperación Española, se celebró en Salamanca, 20 y 21 de marzo de 2014, un importante evento, dedicado a un ámbito de suma importancia como es el de "Desarrollo con equidad. Reducir la desigualdad en los Países de Renta Media. Contribuciones a la agenda post $2015^{7}$.

\section{Un futuro incierto}

Si vinculamos el aumento de los fondos de cooperación a la recuperación económica, los datos inducirían al optimismo. Sin embargo, conviene ser algo más que cautos pues, aunque ya haya algunas señales, la percepción generalizada es que, en algunos terrenos, será imposible recuperar lo perdido.

En el caso de la cooperación, se mantiene el pesimismo, teniendo en cuenta, por ejemplo, la puesta en escena de la Ley de Acción Exterior y del Servicio Exterior del Estado.

La Ley 2/2014, de 25 de marzo, de la Acción Exterior y del Servicio Exterior del Estado fija cinco exigencias fundamentales: afirmar y promover los valores e intereses de España con el objetivo de fortalecer su presencia internacional y reforzar su imagen en el mundo; consolidar y reforzar la credibilidad de España en el exterior... dicha credibilidad es de indudable importancia para aumentar la exportación de bienes y servicios, atraer capitales con los que financiar
La cooperación española, aun reducida,

ha seguido funcionando y se han dado pasos como la renovación del Fondo Español para el Logro de los Objetivos del Milenio

6 Con el titular "España se dispara en los pies”, Ramón Lobo publica un artículo en Tinta Libre, núm. 9, diciembre 2013, afirmando que "los recortes en la ayuda al desarrollo dejan colgados numerosos proyectos con un fuerte coste de imagen y pérdida de influencia. La cooperación internacional de España pasa a ser insignificante”.

7 Ver el documento en

http://www.cooperacionespanola.es/sites/default/files/conclusiones_de_salamanca_desarrollo_con_equidad.pdf 
nuestra economía y facilitar la implantación y expansión de nuestras empresas; fortalecer nuestra participación en el proceso de integración europea; lograr una adecuada coordinación de la Acción Exterior de España con la de los Estados que integran la Comunidad Iberoamericana de Naciones; garantizar una adecuada asistencia y protección a los españoles y apoyar a la ciudadanía española y a las empresas españolas en el exterior. En lenguaje utilizada ya da una pista significativa de cómo entiende el Gobierno la defensa de los intereses de España, priorizando los que afectan a las empresas españolas en el exterior.

En este sentido, queda diluido uno de los objetivos de la política exterior de España como es el de "La lucha contra la pobreza, la solidaridad con los países en vías de desarrollo y el desarrollo económico y social de todos los Estados" (artículo 2, 2, d), que se desarrolla en el artículo 24 (Acción Exterior en materia de cooperación para el desarrollo).

El impacto de la crisis y el manejo que hace de ella el Gobierno se hace notar de nuevo en esta Ley, cuya Disposición adicional décima cuarta establece el "No incremento de gasto público en retribuciones u otros gastos del conjunto del personal del servicio exterior".

Además, por medio de la Disposición final primera, se aprovecha para hacer modificaciones de la Ley 23/1998, de 7 de julio, de Cooperación Internacional para el Desarrollo.

La cooperación española volverá a contar con recursos, en paralelo a la recuperación económica

La Ley también incluye la adopción de la Estrategia de Acción Exterior ("contendrá la expresión ordenada, sectorial y geográfica, de las prioridades y objetivos a medio plazo de la Acción Exterior, y recoge el conjunto de actuaciones de los órganos, organismos y entidades públicas en el exterior a las que dota de coherencia interna”, art. 35) y el Informe de Acción Exterior ${ }^{8}$.

En el caso de la cooperación, sería más que necesario reforzar las sinergias con el cada vez más implantado Servicio Europeo de Acción Exterior (SEAE) y con el conjunto de la cooperación europea que, no olvidemos, también es española, aumentando y mejorando mecanismos como la cooperación delegada, que permitirían a España reforzar desde el esquema europeo su capacidad de trabajo en zonas prioritarias (Norte de África, América Latina...).

Por otro lado, en contra del argumento de que en épocas de crisis no se puede aumentar la ayuda al desarrollo, está el caso del Reino Unido que, con el Gobierno de David Cameron, supera en 2013 el umbral del $0.7 \%$ de la AOD en relación a la Renta Nacional Bruta.

Sin duda, la cooperación española volverá a contar con recursos, en paralelo a la recuperación económica; la duda, más que razonable es que, al igual que otras políticas que afectan directamente al ejercicio de derechos -en este caso el derecho al desarrollo- el Gobierno del Partido Popular tiene la intención de volver a colocar a la política de cooperación como uno de los vectores fundamentales de la acción exterior española.

Y la duda se sustenta en cuanto al modelo de cooperación que subyace a la ideología del Partido que sustenta al Gobierno, cuyos parámetros podemos ubicar en el ámbito de la teoría realista de las Relaciones Internacionales.

8 Las posibles opciones en esta cuestión, en lo que respecta a la cooperación para el desarrollo, se plantean en el análisis del Real Instituto Elcano, como los de Iliana Olivié “¿Qué se puede aprender de la cooperación al desarrollo para el diseño de un sistema de acción exterior?”, o el de José Manuel Argilés Marín "La evaluación de la acción exterior española: reflexiones a partir de la experiencia de evaluación en la política de cooperación internacional para el desarrollo", ambos de 20 de mayo de 2014. 
Para una mayor y mejor cooperación es necesario también reflejar qué supone no sólo como un gasto interno, sino en cuanto a las repercusiones que tiene para una vida mejor de muchos habitantes del planeta. Y también aumentar y mejorar la rendición de cuentas y la transparencia -ha sido muy negativa la repercusión de los desvíos de fondos en la Comunidad Valenciana, con el llamado "caso cooperación" por el que fue condenado el exconseller de Solidaridad y Ciudadanía Rafael Blasco-; entre otras iniciativas, está la de “¿A dónde va el dinero contra la pobreza?”.

Desde el ámbito de actividad del autor de este artículo, es importante además contar con una formación especializada, destinar fondos para investigación en desarrollo, dialogar y ayudar a las entidades académicas que trabajan en este campo, auspiciar la abandonada área de Estudios en Desarrollo y contar con la opinión y el análisis de los especialistas en la materia ${ }^{10}$.

Con la duda sobre cómo va a evolucionar la cooperación española, no podemos terminar este texto sin destacar la enorme importancia de lo que supone, tanto como muestra de solidaridad de la ciudadanía española, del compromiso de las instituciones como reforzamiento del multilateralismo y, sobre todo, para contribuir, como dice la Constitución, a unas relaciones pacíficas y de eficaz cooperación entre todos los pueblos de la Tierra.

\section{Bibliografía}

Alonso, J. A., y Ocampo, J. A. (dirs.). (2011). Cooperación para el desarrollo en tiempo de crisis. México: Fondo de Cultura Económica.

Amnistía Internacional, Greenpeace e Intermón Oxfam. (2013, 26 de noviembre). Combatir la crisis con dignidad y derechos. Recuperado de http://www.oxfamintermon.org/es/documentos/26/11/13/combatir-crisis-con-dignidad-derechos

Argilés Marín, J. M. (2014, 20 de mayo). La evaluación de la acción exterior española: reflexiones a partir de la experiencia de evaluación en la política de cooperación internacional para el desarrollo. Estrategia Exterior Española 15/2014. Real Instituto Elcano. Recuperado de http://www.realinstitutoelcano.org/wps/portal/rielcano/contenido?WCM_GLOBAL_ CONTEXT=/elcano/elcano_es/zonas_es/politicaexteriorespanola/eee15-2014-argilesevaluacion-accion-exterior-espanola-reflexiones-experiencia-cooperacion-desarrollo

Arias, M. (2014, 9 de febrero). Declaraciones recogidas en A. M. Nimo, La cooperación es una fuente de prestigio para España que no debe perderse. El Mundo. Recuperado de http:// www.elmundo.es/internacional/2014/02/09/52f1237eca4741d4038b456c.html

Atienza, J. (2013). La Realidad de la Ayuda 2013. Oxfam Intermón. Recuperado de http://www. oxfamintermon.org/es/informate/publicaciones/estudios/realidad-de-ayuda-2014

Bandeira, P. (2014, 10 de julio). La Cooperación Internacional del Gobierno de España en la presente legislatura. Mesa redonda DECIDE (Democracia, Ciudadanía, Desarrollo).

9 Fundación porCausa, http://porcausa.org/ayuda-desarrollo/. Revela el caso de las Fundaciones vinculadas a partidos políticos con representación parlamentaria: cerca de 25 millones de euros entre 1995 y 2012, la gran mayoría destinadas a organizaciones vinculadas a los partidos en el Gobierno (FAES o Ideas) y con una trayectoria cuestionable en el campo de la cooperación internacional.

10 Véase el Documento "Reconstruyendo la cooperación desde sus profesionales: propuestas para una reflexión", disponible en la página web del CIDOB, www.cidob.org. 
Cascante, K. (2013). La cooperación española al desarrollo abandona la lucha contra la pobreza. Economía Exterior, núm. 67, invierno 2013/2014, pp. 105-112.

Comisión Europea. (2013). Eurobarómetro: Ayuda al desarrollo y objetivos de desarrollo del milenio de la UE. Recuperado de europa.eu/public_opinion/archives/ebs/ebs_405_fact_es_ es.pdf

Coordinadora de ONGD-España. (2013). Los PGE2014 rematan a una cooperación ya prácticamente desmantelada. Recuperado de http://www.congde.org/contenidos/los-pge2014rematan-a-una-cooperacion-ya-practicamente-desmantelada

De la Iglesia-Caruncho, M. (2011). Política exterior y política de cooperación: ¿amistades peligrosas?. East Sussex: Fundación Carolina.

Fanjul, G. (2012, 27 de septiembre). No hay Consejo de Seguridad sin cooperación. Blog 3500 Millones, El País. Recuperado de http://blogs.elpais.com/3500-millones/2012/09/ no-hay-consejo-de-seguridad-sin-cooperacion.html

García-Margallo, J. M. (2012). Discursos y declaraciones del Ministro de Asuntos Exteriores y de Cooperación D. José Manuel García-Margallo y Marfil. 2012 Enero-Diciembre. Oficina de Información Diplomática, Ministerio de Asuntos Exteriores y de Cooperación. Recuperado de http://www.exteriores.gob.es/Portal/es/SalaDePrensa/Multimedia/Publicaciones/Documents/2012_discursosMAEC.pdf

Gómez Gil, C. (2013). Desguazando la cooperación española. La construcción ideológica de colapso de la cooperación al desarrollo. Papeles de relaciones ecosociales y cambio global, núm. 123, pp. 85-95.

Gómez Gil, C. (2013). La voladura de la cooperación española. Indicadores para confirmar el deliberado colapso de la política de AOD. En Varios autores, Los futuros de la cooperación en tiempos de crisis. El rapto de Europa, núm. 23-24, pp. 70-80.

Larrú, J. M. (2013). La AOD española en la actualidad. En Varios autores, Los futuros de la cooperación en tiempos de crisis. El rapto de Europa, núm. 23-24, pp. 60-70.

Ley 23/1998, de 7 de julio, de Cooperación Internacional para el Desarrollo. Boletín Oficial del Estado, 9 de julio de 1998, núm. 162.

Ley 2/2014, de 25 de marzo, de la Acción y del Servicio Exterior del Estado. Boletín Oficial del Estado, 26 de marzo de 2014, núm. 74, pp. 26531 a 26564.

Lobo, R. (2013). España se dispara en los pies. Tinta Libre, núm. 9, diciembre 2013.

Lomøy, J. (2013, 13 de diciembre). Mid-term Review of Spain, 19 november 2013, Madrid. Carta a los delegados y observadores del Comité de Ayuda al Desarrollo (CAD), OCDE. Recuperado de http://www.oecd.org/dac/peer-reviews/MTR_SPAIN_2013.pdf

Manglano, P. (2007). La ayuda al desarrollo como incentivo del buen gobierno. Cuadernos de pensamiento político FAES, n. 13, Enero/Marzo 2007, pp. 159-169.

Martínez, P., y Martínez, I. (2014). Ruptura del consenso y desmantelamiento: un análisis de la cooperación española. Anuario 2013. Hacia 2015: Visiones del desarrollo en disputa. XI Informe Anual de la Plataforma 2015 y más. Recuperado de http://www.2015ymas.org/ 
Millán Acevedo, N. (2014, 9 de abril). Una marca desvinculada del desarrollo humano. El País. Recuperado de http://elpais.com/elpais/2014/04/01/planeta_futuro/1396372626_005272. html

Ministerio de Asuntos Exteriores y de Cooperación (ed.). (2012). Plan Director de la Cooperación Española 2013/2016. Recuperado de http://www.cooperacionespanola.es/sites/ default/files/plan_director_cooperacion_espanola_2013-2016.pdf

Moratinos, M. A. (2010). Declaraciones recogidas en Europa Press, El Gobierno asume que no alcanzará la meta del 0,7 en ayuda al desarrollo para 2012. Europa Press. Recuperado de http://www.europapress.es/epsocial/noticia-gobierno-asume-no-alcanzara-meta-07-ayuda-desarrollo-2012-20100512154526.html

Olivié, I. (2013). ¿Cumpleaños feliz? 25 años de la Aecid. Política Exterior, noviembre/diciembre 2013, pp. 106-114.

Olivié, I. (2014, 20 de mayo). ¿Qué se puede aprender de la cooperación al desarrollo para el diseño de un sistema de acción exterior?. Estrategia Exterior Española 16/2014. Real Instituto Elcano.

Organización Mundial de la Salud. (2014). Estadísticas Sanitarias Mundiales 2014.

Rajoy, M. ( 2011, 19 de diciembre). Discurso de Investidura del Presidente del PP, Mariano Rajoy. Congreso de los Diputados, 19 de diciembre de 2011. El País. Recuperado de http://politica.elpais.com/especiales/2011/nuevo-gobierno/sesion-de-investidura/

Rajoy. (2013). El presidente del Gobierno, Mariano Rajoy, habla ante la Asamblea General de la ONU. Consejería de Información, Misión Permanente de España ante las Naciones Unidas. Recuperado de http://www.spainun.org/2013/09/el-presidente-del-gobiernomariano-rajoy-habla-ante-la-asamblea-general-de-la-onu/

Robles Orozco, G. (2014, 16 de enero). Declaraciones recogidas en A. Agudo Lazareno, Hay que ayudar a los países de renta media. El 70\% de la pobreza está allí. El País. Recuperado de http://elpais.com/elpais/2014/01/02/planeta_futuro/1388692957_485741.html

Rodríguez Zapatero, J. L. (2010, 12 de mayo). Discurso del Presidente del Gobierno en la comparecencia para informar de la reunión extraordinaria del Eurogrupo en relación con el rescate de Grecia y la situación de los mercados financieros. Congreso de los Diputados, 12 de mayo de 2010. El País.

Ruiz-Giménez, M. (2013, 10 de octubre). Declaraciones recogidas en J. Vargas, España retrocede 20 años en Ayuda Oficial al Desarrollo. Público. Recuperado de http://www.publico.es/espana/473983/espana-retrocede-20-anos-en-ayuda-oficial-al-desarrollo

Ruiz-Giménez, M. (2013, 19 de diciembre). Declaraciones recogidas en Europa Press, Los Presupuestos de 2014 abocan a millones de personas a la pobreza. Europa Press. Recuperado de http:/www.europapress.es/sociedad/noticia-pge-mas-400-ong-denuncian-presupuestos-2014-abocan-millones-personas-pobreza-desigualdad-20131219121426.html

Santander Campos, G., y Millán Acevedo, N. (2014). La política diplomática española y la defensa de los derechos humanos. Un análisis desde la coherencia de políticas para el desarrollo. Cuadernos 2015 y más, n. 3. Recuperado de http:/www.2015ymas.org/ centro-de-documentacion/publicaciones/2014/1584/la-politica-diplomatica-espanola-yla-defensa-de-los-derechos-humanos/ 
Sotillo, J. A. (2010). La cooperación al desarrollo, el nuevo reto de la política exterior española. En J. C. Pereira (coord.), La politica exterior de España. De 1800 hasta hoy. (pp. 345366). Barcelona: Ariel.

Sotillo, J. A. (2012). La cooperación española en la unidad de cuidados intensivos. Tiempo de Paz, núm. 105, 2012, pp. 5-14.

Toharia, M. (2014). La ayuda al desarrollo, un deber moral para el $81 \%$ de españoles. Encuesta de Metroscopia para planeta futuro. El País. Recuperado de http://elpais.com/ elpais/2014/02/05/planeta_futuro/1391619729_567890.html

Varios autores. (2013). Los futuros de la cooperación en tiempos de crisis. El rapto de Europa, núm. 23-24, diciembre de 2013. 